\title{
SENSORY PROPERTIES OF HIGH-PRESSURE-TREATED MILK
}

\author{
Marika Liepa*, Jelena Zagorska, Ruta Galoburda, Evita Straumite, Zanda Kruma, Martins Sabovics \\ Department of Food Technology, Faculty of Food Technology, Latvia University of Agriculture, Rigas iela 22, Jelgava, Latvia, \\ e-mail:marikaliepa@gmail.com
}

\begin{abstract}
The acceptance and preference of milk and dairy products by consumers is determined by the products sensory characteristics. High pressure processing (HPP) can be applied as an alternative to thermal treatment to provide that sensory quality remains unaffected. The aim of this work was to evaluate the influence of high-pressure treatment on the acceptance of the sensory profile of milk, compared to untreated and thermally-treated milk. Milk was processed at $400 \mathrm{MPa}$ or pasteurized at $78{ }^{\circ} \mathrm{C}$ for $15-20$ seconds. Sensory evaluation of milk samples was carried out in two different groups - untrained panellists (at the international food industry fair 'Riga Food 2016') and trained panellists (finished basic course of sensory evaluation). Both groups evaluated the samples using a five point hedonic scale. The hedonic evaluation of liking of untreated, pasteurized and high-pressure treated milk samples' sensory properties showed that there were no significant differences ( $p>0.05$ ) in aroma, but there were significant differences in the liking of milk samples colour, taste and aftertaste $(\mathrm{p}<0.05)$ depending on treatment type. The overall sensory properties of HP-treated milk were evaluated higher comparing to the traditionally pasteurized milk. The colour (which was measured in CIE L*a*b* colour system) difference was well visible in high-pressure treated milk in comparison to untreated and pasteurized milk.
\end{abstract}

Keywords: milk, high pressure, sensory properties, colour.

\section{Introduction}

Many activities in the food sector are devoted to improving already existing products and developing new products for the purpose of satisfying consumer preferences and needs (Næs et al., 2010). Nowadays consumers demand high quality foods, which are fresh, natural, free from chemical preservatives, nutritionally richer and microbiologically safe, but with extended shelf-life.

Milk is a widely consumed beverage due to its nutritional importance, a pleasant aroma and mouth feel, and a slightly sweet taste (Chugh et al., 2014). Milk and dairy products are treated at temperature range from 70 to $145^{\circ} \mathrm{C}$ ensuring the safety and stability of the product during its shelf life. Unfortunately thermal treatments above $100{ }^{\circ} \mathrm{C}$ lower the nutritional quality of milk because many nutrients are heat labile. Furthermore, heat treatment is known to cause changes in the flavour of milk. Gandy et al. (2008), Walstra et al. (2006) established that heat treatments $\left(72-145^{\circ} \mathrm{C}\right.$ ) cause changes in sensory quality of milk with the development of tastes, such as a cooked or caramel flavour, and odours, such as a cooked smell.

To overcome this problem in recent years, several nonthermal technologies (hurdle technology, high hydrostatic pressure, power ultrasonic, pulsed electric field, etc.) have been explored to meet new demands of consumers for fresh products without food additives. Among these technologies, high-pressure processing (HPP) seems to be promising one for food applications (Chopde et al., 2014) and at this moment is the most commercially developed non-thermal technology, with very good acceptance by consumers (Bello et al., 2014). One of the important goals of milk preservation methods by its high-pressure treatment is to reduce microbial loads and inactivate enzymes. Pressure ranges between 100 and $1200 \mathrm{MPa}$ have been considered as effective to inactivate microorganisms including food-borne pathogens (Chawla et al., 2011). At the same time this technology is capable to introduce the least possible undesired changes of physicochemical and sensory properties of product, as well as preservation of its nutritional value (Popov-Raljić et al., 2008). Hogan et al. (2005) reported that high pressure treatment at moderate pressure generally results in minimal changes in the odour, flavour, or other sensory characteristics of foods.

Sensory analysis is the most straight forward way to evaluate the quality and consumer acceptance of food products (Hogan et al., 2005). So far, few studies (Andres et al., 2016; Contador et al., 2015; Fitria et al., 2015; Gervilla et al., 2001; Trujillo et al., 2002) have been conducted to assess the effect of HPP on the volatile profile and sensory quality of milk, and these preliminary results are encouraging. Young and George (2013) established that consumer perception about non-thermal treatments is that they provide more natural or fresher foods than the heat treated samples. The aim of this work was to evaluate the influence of high-pressure treatment on the acceptance of the sensory profile of milk, compared to untreated and thermallytreated milk.

\section{Materials and Methods}

Individual cow milk samples were collected from the morning milking during sampling procedure of milk quality monitoring according to the standard LVS 175:1999 'Sampling of raw milk'. After collection, milk samples were transported to the laboratory of the Faculty of Food Technology, Latvia University of Agriculture.

Processing of milk samples

For obtaining maximally equal samples milk was mixed ( $2 \mathrm{~min}$ ) and filled in polyethylene terephthalate (PET) plastic bottles (NF2 - Ø28 mm, $120 \pm 10 \mathrm{~mL}$ ). Milk samples were pressurized in the Iso-Lab High Pressure Pilot Food Processor S-FL-100-250-09-W, (Stansted Fluid Power LTD, UK) with a pressure chamber of $10 \mathrm{~cm}$ diameter and $23 \mathrm{~cm}$ length. Milk underwent high pressure treatment at $400 \mathrm{MPa}$ for 15 minutes. The pressurization was completed at room temperature. 
Product temperature increased during pressurization up to $30{ }^{\circ} \mathrm{C}$ and dropped during pressure release to about $17{ }^{\circ} \mathrm{C}$.

High pressure processing was compared to the thermal processing (high-temperature short-time (HTST) pasteurization at $78{ }^{\circ} \mathrm{C}$ for $15-20 \mathrm{~s}$ ).

\section{Sensory analysis}

Sensory evaluation of milk samples was organized in two-steps:

1. in the evaluation at the international food industry fair Riga Food 2016 participated totally 55 untrained panellists (80\% women and $20 \%$ men), who represented all Latvia regions: Riga (36.4\%), Zemgale $(22.7 \%)$, Latgale (18.2\%), Vidzeme $(13.6 \%)$ and Kurzeme $(9.1 \%)$. There were three noticeably larger panellists groups: up to 20 years $(22.7 \%)$, from age 21 to $40(27.3 \%)$ and from age 41 to $60(36.4 \%)$, while the smallest group of panellists (13.6\%) was aged 61 and older. More than half of untrained panellists $(54.5 \%)$ were aware that high-pressure technology can be applied in the manufacture of foods, what may indicate their relation to food technology area;

2. in the evaluation at Latvia University of Agriculture, Faculty of Food Technology participated 25 trained panellists (92\% women and $8 \%$ men). The sensory evaluation tests were performed in individual cabins with controlled temperature and lighting conditions. A preference test was used to evaluate the acceptance of the sample sensory properties. Panellists used a 5-point hedonic scale (Meilgaard et al., 1991) ranging from 1 (dislike very much) to 5 (like very much) for scoring the following sensory properties of milk: colour, aroma, taste and aftertaste.

The panellists received approximately $30 \mathrm{~mL}$ of each sample at $16 \pm 2{ }^{\circ} \mathrm{C}$ temperature in cups with a volume of $50 \mathrm{~mL}$, coded with three-digit random numbers. Warm water was provided to the panellist for cleansing palate between sampling.

\section{Instrumental evaluation of colour}

Before instrumental evaluation of colour milk was thoroughly mixed and filled in Petri dish.

The colour parameters of milk samples were measured in CIE L*a*b* colour system by direct reading using the colorimeter Colour Tec - PMC (Accuracy Microsensors, USA).

The following colour parameters were evaluated: $\mathrm{L}^{*}-$ lightness is ranging from 0 (black) to 100 (perfect white); $a^{*}$ - redness to greenness (positive to negative values, respectively); $b^{*}-$ yellowness to blueness (positive to negative values, respectively). The values provided for each sample were the average of ten replicates.

In order to compare the total colour difference $(\Delta \mathrm{E})$ between milk samples, the following equation (1) was utilized:

$$
\Delta E=\sqrt{\left(L-L_{0}\right)^{2}+\left(a-a_{0}\right)^{2}+\left(b-b_{0}\right)^{2}}
$$

Depending on the value of $\Delta \mathrm{E}$ the colour difference between the milk samples could be estimated as not noticeable $(0-0.5)$, slightly noticeable (0.5-1.5), noticeable (1.5-3.0), well visible (3.0-6.0) and great (6.0-12.0) (Cserhalmi et al., 2006).

\section{Data analysis}

The processing of the obtained data was performed using mathematical and statistical methods with Microsoft Excel software (Microsoft Office Enterprise 2007, License: Shareware N/A). The results represent the mean \pm standard deviations, and were analysed using analysis of variance (ANOVA) and Tukey's test when significant differences among the milk samples were found (Næs et al., 2010). Statistical differences with $\mathrm{p}$-values under 0.05 were considered as significant.

\section{Results and Discussion}

Sensory evaluation at the international food industry fair Riga Food 2016 - untrained panellists

Sensory properties of the product are the main parameters, which are used by customers for choosing appropriate food products, therefore the current research aimed to indicate HPP influence on milk sensory properties and compare it with traditional pasteurized milk. In the current sensory evaluation step, untrained panellists evaluated overall acceptance of sensory properties (colour, aroma, taste and aftertaste) of pasteurized (PM) and high-pressure processed (HPM) milk samples.

The evaluation of milk sensory properties by untrained panellists was analysed in both samples, and the results are presented in Table 1.

According to the statistical analysis, there was no significant difference $(\mathrm{p}>0.05)$ in the liking of pasteurized and pressure-treated milk samples aroma. In the hedonic scale panellists rated aroma of PM and HM sample in the range from 3 (neither like nor dislike) to 5 (like very much).

Table 1

Sensory evaluation of milk samples by respondents at the international food industry fair

\begin{tabular}{lcc}
\hline Sensory & \multicolumn{2}{c}{ Milk samples } \\
\cline { 2 - 3 } properties & PM & HPM \\
\hline Aroma & $4.09 \pm 0.3 \mathrm{a}$ & $4.36 \pm 0.9 \mathrm{a}$ \\
Colour & $3.91 \pm 0.6 \mathrm{a}$ & $4.63 \pm 0.7 \mathrm{~b}$ \\
Taste & $3.82 \pm 0.7 \mathrm{a}$ & $4.36 \pm 0.9 \mathrm{~b}$ \\
Aftertaste & $4.00 \pm 0.7 \mathrm{a}$ & $4.50 \pm 0.7 \mathrm{~b}$ \\
\hline
\end{tabular}

PM - pasteurized milk, HPM - high-pressure processing milk *values marked with the same letters in the rows are not significantly different $(\mathrm{p}>0.05)$

Evaluation of acceptance of pasteurized and highpressure processed milk sensory properties shows that there are significant differences in colour $(\mathrm{p}=0.022)$, taste $(\mathrm{p}=0.019)$, and aftertaste $(\mathrm{p}=0.038)$.

The current evaluation demonstrates that some sensory properties of HP milk, were preferred comparing with PM. Next step of the research was to detect if pressurized milk had similar sensory properties comparing with untreated milk, although in scientific literature (Andres et al., 2016; Fitria et al., 2015; 
Trujillo et al., 2002) is mentioned, that HPP doesn't affect it.

Sensory evaluation at LLU, Faculty of Food Technology - trained panellists

Untreated, pasteurized and high pressure-treated milk samples were evaluated based on their sensory attributes: aroma, colour, taste, and aftertaste. Trained panellists evaluated sensory properties of milk samples in the range from 3 (neither like nor dislike) to 5 (like very much).

The diagram given in Figure 1 illustrates the results of the evaluation of sensory properties by trained panellists.

According to ANOVA, there were significant differences in degree of liking among the three milk samples colour $(\mathrm{p}=0.000)$, taste $(\mathrm{p}=0.000)$, and aftertaste $(p=0.002)$. Results of the hedonic scores show that there are no differences $(\mathrm{p}=0.103)$ in the preference of three milk samples aroma.

The sample UM had the highest degree of preference compared to samples HPM and PM.

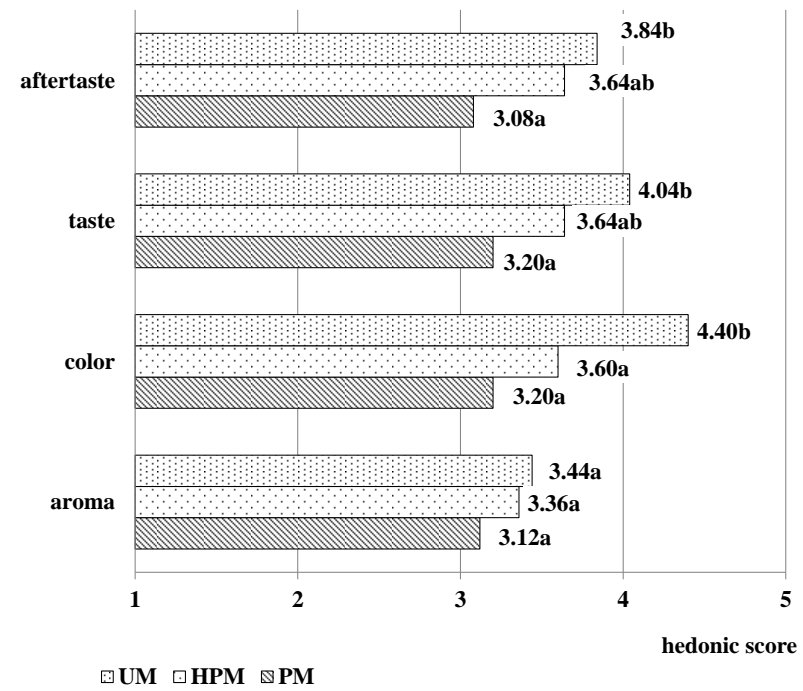

Figure 1. Sensory evaluation of preference of milk samples properties completed by trained panellists

UM - untreated milk, HPM - high-pressure processing milk, PM - pasteurized milk

*values marked with the same subscript letters are not significantly different $(\mathrm{p}>0.05)$

The aroma of the sample HPM remained stable after high-pressure processing with score $3.36 \pm 0.96$, and there was noted no significant difference compared to the sample UM (mean score: $3.44 \pm 0.72$ ). This is in agreement with observations by Chawla et al. (2011), who reported that flavour compounds remain unaffected by HP treatment. Also Vazquez-Landaverde et al. (2006) reported that high-pressure processing at low temperature causes minimum change of the volatile composition of milk. Although sample PM had the lowest mean score $(3.12 \pm 0.44)$, there was no significant difference ( $p>0.05$ ) from the samples UM and HPM.

The trained panellists found significant differences $(p<0.05)$ in taste and aftertaste according to the type of milk treatment. The sample UM had the highest mean score of taste $(4.04 \pm 0.61)$ and aftertaste $(3.84 \pm 0.63)$ among all milk samples. No significant differences from the sample UM were detected in sample HPM. However, the mean scores of taste and aftertaste of sample PM revealed significant decrease in the degree of liking compared with the control sample (UM).

The obtained results are in agreement with the research results of Popov-Raljić et al. (2008) and Hogan (2005) and can be evaluated positively, HPM sample combines pasteurised and untreated milk properties: is microbiologically safe and with sensory properties, which are close to untreated milk .

Colour of UM had the highest degree of liking therefore for better understanding, which milk colour nuances are preferred by panellists and how milk was changed after different treatment technologies instrumental evaluation of colour was completed.

Instrumental evaluation of colour

White colour of milk is due to scattering of light particles by fat globules and casein micelles (Naik et al., 2013). Hunter Luminance value (L* value) of milk is generally used as a measure of whiteness (Harte et al., 2003).

The results of colour CIE L*a*b* measurements of the milk samples are shown in Table 2.

A moderately intense heat treatment causes colour changes, presumably due to serum protein denaturation and aggregation. As a result pasteurized milk become a whiter (Walstra et al., 2006; Chopde et al. 2014). Also in the present study, pasteurized milk was whiter comparing with sample HPM resulting in higher $\mathrm{L}^{*}$ values.

Table 2

Colour values of milk samples in CIE $\mathbf{L a b}$ system

\begin{tabular}{lccc}
\hline \multirow{2}{*}{ Parameter } & \multicolumn{3}{c}{ Milk samples } \\
\cline { 2 - 4 } & UM & PM & HPM \\
\hline $\mathrm{L}^{*}$ & $89.08 \pm 0.1$ & $90.05 \pm 0.18$ & $84.31 \pm 0.16$ \\
$\mathrm{a}^{*}$ & $-2.5 \pm 0.21$ & $-2.48 \pm 0.18$ & $-2.62 \pm 0.25$ \\
$\mathrm{~b}^{*}$ & $6.67 \pm 0.46$ & $6.52 \pm 0.69$ & $7.66 \pm 0.57$ \\
\hline
\end{tabular}

UM - untreated milk, PM - pasteurized milk, HPM - highpressure processing milk

After high-pressure processing colour parameter $\mathrm{L}^{*}$ value of whole milk decreased, indicating significant changes $(p<0.005)$ comparing to UM. This is in agreement with observations by Kim et al. (2008), who reported that the $\mathrm{L}^{*}$ value of $\mathrm{HP}$ treated (at $200 \mathrm{MPa}$ ) whole milk was significantly lower than that of the raw milk.

Similar tendency was established by Naik et al. (2013) in skimmed milk after treatment at 250-450 MPa, significant decrease in the $\mathrm{L}^{*}$ value was observed, and in ewe`s milk, by Gervilla et al. (2001). Also Harte et al. (2003) reported that milk subjected to HP treatment and thermal treatment followed by HP, loses its white colour and turns yellowish.

Johnston et al. (1992) proposed that the decrease in $\mathrm{L}^{*}$ value could have been mainly due to disintegration of casein micelles by pressure into small fragments and that might be a possible explanation for obtained results in our research. Obtained changes of $\mathrm{L}^{*}$ value in milk 
can be explained also with denaturation of whey proteins during pressurizing (Pandey et al., 2003), but for significant conclusion further studies should be done evaluating milk structure.

Colour parameter $a^{*}$ of pressurized milk was lower comparing with samples UM and PM, but difference was not significant $(p>0.05)$. Meanwhile, high-pressure treatment caused a significant $(\mathrm{p}<0.005)$ increase in the $b^{*}$ value (yellowness) when compared with unprocessed milk. The increase was more pronounced comparing with pasteurized samples.

The total colour difference $(\Delta \mathrm{E})$ indicates the magnitude of colour difference between processed and unprocessed fluid foods (Barba et al., 2012). The calculated values for total colour change in milk samples are provided in Table 2.

Table 2

Colour difference $(\Delta E)$ of milk samples

\begin{tabular}{lccc}
\hline \multirow{2}{*}{ Sample } & \multicolumn{3}{c}{ Sample } \\
\cline { 2 - 4 } & UM & PM & HPM \\
\hline UM & 0 & & \\
PM & 0.98 & 0 & 0 \\
HPM & 4.87 & 5.85 & 0 \\
\hline UM - untreated milk, PM - pasteurized milk, HPM - high-
\end{tabular}

UM - untreated milk, PM - pasteurized milk, HPM - highpressure processing milk

According to the classification of Cserhalmi et al. (2006), colour differences were slightly noticeable $(0.5<\Delta \mathrm{E}<1.5)$ in pasteurized milk, and well visible for sample HPM, comparing with UM. The colour difference between samples HPM and PM was well visible $(3<\Delta \mathrm{E}<6)$ to the human eyes.

Obtained results are unambiguous, according to the data obtained in Table 2, well visible difference was established between PM and HPM milk, but sensory evaluation results (Fig. 1) indicated no significant difference $(p>0.05)$ between the degree of liking of the same samples. Combining results of sensory and instrumental evaluation of colour unexpected conclusion of the current results can be drawn panellists prefer white milk, over the yellowish one.

\section{Conclusions}

The hedonic evaluation of untreated, pasteurized and high-pressure treated milk samples showed no significant differences ( $p>0.05)$ in aroma, but there were significant differences in the liking of milk samples colour, taste and aftertaste $(\mathrm{p}<0.05)$.

Although high-pressure treatment cannot retain the original sensory properties of raw milk, the overall sensory properties (colour, taste and aftertaste) of HP-treated milk were evaluated higher comparing to the traditional pasteurized milk.

In the present study all the CIE L*a*b* colour parameters were changed by the high-pressure treatment: significant decrease $(\mathrm{p}<0.05)$ of the $\mathrm{L}^{*}$ value and increase of $b^{*}$ value was observed, whereas the value of colour parameter $a^{*}$ increased insignificantly ( $p>0.05)$. The total colour difference was well visible in high-pressure treated milk in comparison to untreated and pasteurized milk.

\section{Acknowledgment}

Present research has been supported by the program "Strengthening Research Capacity in the Latvia University of Agriculture".

\section{References}

1. Andres V., Villanueva M., Tenorio M. (2016) Influence of high pressure processing on microbial shelf life, sensory profile, soluble sugars, organic acids, and mineral content of milk- and soy-smoothies. LWT - Food Science and Technology, Vol. 65, p. 98-105.

2. Barba F. J., Esteve M. J., Frígola A. (2012) High pressure treatment effect on physicochemical and nutritional properties of fluid foods during storage: A review. Comprehensive Reviews in Food Science and Food Safety, Vol. 11(3), p. 307-322.

3. Bello E., Martínez G., Ceberio B., Rodrigo D., López A. (2014) High pressure treatment in foods. Foods, Vol. 3(3), p. 476-490.

4. Chawla R., Patil G., Singh A. (2011) High hydrostatic pressure technology in dairy processing: A review. Journal of Food Science and Technology, Vol. 48(3), p. 260-268.

5. Chopde S. S., Deshmukh M. A., Kalyankar S. D., Changade S. P. (2014) Applications of high pressure technology for milk processing. Research Journal of Animal Husbandry and Dairy Science, Vol. 5(2), p. 143-147.

6. Chugh A., Khanal D., Walkling-Ribeiro M., Corredig M., Duizer L., Griffiths M. (2014) Change in colour and volatile composition of skim milk processed with pulsed electric field and microfiltration treatments or heat pasteurization. Foods, Vol. 3(2), p. 250-268.

7. Contador R., Delgado F. J., García-Parra J., Garrido M., Ramírez R. (2015). Volatile profile of breast milk subjected to high-pressure processing or thermal treatment. Food Chemistry, Vol. 180, p. 17-24.

8. Cserhalmi Z., Sass-Kiss Á., Tóth-Markus M., Lechner N. (2006). Study of pulsed electric field treated citrus juices. Innovative Food Science and Emerging Technologies, Vol. 7(1-2), p. 49-54.

9. Fitria A., Buckow R., Singh T., Hemar Y., Kasapis S. (2015) Colour change and proteolysis of skim milk during high pressure thermal - processing. Journal of Food Engineering, Vol. 147, p. 102-110.

10. Gandy A. L., Schilling M. W., Coggins P. C., White C. H., Yoon Y., Kamadia V. V. (2008) The effect of pasteurization temperature on consumer acceptability, sensory characteristics, volatile compound composition, and shelf-life of fluid milk. Journal of Dairy Science, Vol. 91(5), p. 1769-1777.

11. Gervilla R., Ferragut V., Guamis B. (2001) High hydrostatic pressure effects on colour and milk-fat globule of ewe's milk. Journal of Food Science, Vol. 66(6), p. 880-885.

12. Harte F., Luedecke L., Swanson B., BarbosaCánovas G. V. (2003) Low-fat set yogurt made from milk subjected to combinations of high hydrostatic pressure and thermal processing. Journal of Dairy Science, Vol. 86(4), p. 1074-1082.

13. Hogan E., Kelly A.L., Sun D.W. (2005) High pressure processing of foods: an overview. In: Emerging Technologies for Food Processing. 2nd Ed. Sun Da-Wen (ed). Amsterdam: Elsevier, p. 3-31.

14. Johnston D.E., Austin B.A., Murphy P.M. (1992) Effects of high hydrostatic pressure on milk. Milchwiss, Vol. 47, 
p. $760-763$.

15. Kim H.Y., Kim S.H., Choi M.J., Min S.G., Kwak H.S. (2008) The effect of high pressure-low temperature treatment on physicochemical properties in milk. Journal of Dairy Science, Vol. 91(11), p. 4176-4182

16. Meilgaard M., Civille G.V., Carr B.T. (1991) Sensory Evaluation Techniques, 2nd Ed., Florida: CRC Press Inc. $464 \mathrm{p}$.

17. Næs T., Brockhoff P. B., Tomic O. (2010) Statistics for Sensory and Consumer Science. West Sussex: John Wiley \& Sons Ltd. $301 \mathrm{p}$.

18. Naik L., Sharma R., Rajput Y. S., Manju G. (2013) Application of high pressure processing technology for dairy food preservation - future perspective: A review. Journal of Animal Production Advances, Vol. 3(8), p. 232-241.

19. Pandey P. K., Ramaswamy H. S., St-Gelais D. (2003) Effect of high pressure processing on rennet coagulation properties of milk. Innovative Food Science \& Emerging Technologies, Vol. 4(3), 245-256.
20. Popov-Raljić J. V., Lakić N. S., Laličić-Petronijević J. G., Barać M. B., Sikimić V. M. (2008) Colour changes of UHT milk during storage. Sensors, Vol. 8(9), p. 5961-5974.

21. Trujillo A. J., Capellas M., Saldo J., Gervilla R., Guamis B. (2002) Applications of high-hydrostatic pressure on milk and dairy products: A review. Innovative Food Science and Emerging Technologies, Vol. 3(4), p. 295-307.

22. Vazquez-Landaverde P. A., Torres J. A., Qian M. C. (2006) Effect of high-pressure-moderate-temperature processing on the volatile profile of milk. Journal of Agricultural and Food Chemistry, Vol. 54(24), p. 9184-9192.

23. Walstra P., Wouters J. T. M., Geurts T. J. (2006). Dairy Science and Technology (Second). Taylor \& Francus Group, LLC.

24. Young W. P., George F. W. H. (2013) Milk and Dairy Products in Human Nutrition. West Sussex: John Wiley \& Sons Ltd. 742 p. 